\title{
Health Literacy: A Universal Call to Action
}

\section{Virginia E. Koenig}

Touro College, 320 West 31st Street New York, NY 10001, USA, 516-446-0082

\author{
Corresponding Author : Virginia E. Koenig, Touro College, New York, NY 10001, USA. E-mail: Virginia.koenig@touro.edu \\ Received date: January 23, 2019;Accepted date : February 05, 2019; Published date: February 07, 2019. \\ Citation : Virginia E. Koenig, Health Literacy: A Universal Call to Action, J. Psychology and Mental Health Care. \\ Doi: 10.31579/2637-8892.19/011.
}

Copyright : (c) 2019 Virginia E. Koenig. This is an open-access article distributed under the terms of The Creative Commons Attribution License, which permits unrestricted use, distribution, and reproduction in any medium, provided the original author and source are credited.

\section{Introduction}

Health literacy is the ability to access, understand, evaluate, and communicate information that promotes, maintains, and improves health care in a variety of settings across the lifespan. Unlike general literacy, health literacy is considered a more dynamic and contextreliant ability because it is comprised of reading comprehension, reasoning, and numeracy skills [1]. Because health literacy is multifactorial, it may be extremely difficult for low-health literate individuals to effectively act on information provided to them by clinicians and other health care professionals. In the USA alone, lowhealth literacy threatens up to 70 percent of populations regardless of gender, race, education, or level of income. Literature reviews funded by the Agency for Healthcare Research and Quality (AHRQ), a Division of the United States (U.S.) Department of Health and Human Services indicates that about one-third of U.S. adults have low-health literacy. That figure rises to 41 percent for adults 65-75 years of age, and 70 percent for individuals over the age of 75 [2]. Low-health literacy is estimated to cost billions of dollars per year, and cannot be detected by physical examination, blood test, or state of the art equipment [3]. For these reasons, a number of stakeholders consider low-health literacy a silent epidemic.

In response to concerns regarding a health literacy silent epidemic, the AHRQ commissioned the Health Literacy Universal Precautions Toolkit (Toolkit). The Toolkit is a public domain, online resource that provides clinicians and other health care professionals with a systematic approach to reducing complexities associated with lowhealth literacy. The Toolkit is aimed at improving the provision of care and outcomes for low-health literate persons [4]. A universal precautions approach to health literacy allows health care organizations and professionals to assume that all patients have trouble comprehending health information; therefore, professionalpatient communication should be performed in ways that anyone can understand. Evidence indicates that health care professionals frequently provide their patients with a great deal of information using unfamiliar medical jargon and technical terminology. Furthermore, health care professionals infrequently assess and confirm patients' understanding of provided information [1]. Studies support that simplifying oral and written communication, and confirming comprehension of medical information with all patients can reduce the risk of miscommunication [3]. A universal precautions approach to health literacy promotes the use of strategies and techniques that support clear communication that can optimize patient care and outcomes [5].

The Toolkit emphasizes professionals' routine practice of patientcentered communication, including the reinforcement of learned information via the teach-back method [6]. Tool \#5 of the Toolkit [4] explains how to use the teach-back method and why it is a valuable tool that can be used to:

- Improve patients' understanding of and adherence to medical regimens
- $\quad$ Decrease call-backs and cancelled appointments

- Improve the provision of services and patient satisfaction

- Optimize patient outcomes and increase sustainability of recommended regimens.

When routinely used, a universal precautions approach to health literacy supports patients' efforts to improve their medical self-management, health, wellness, and quality of life [7]. Ultimately, consistent use of universal precautions can render organizational environments and health care systems easier to navigate and more efficient.

\section{Health Literacy: A Call to Action}

Evidence indicates that the bulk of literature on health literacy has consistently focused on patient factors, with significantly less emphasis on the communication skills and practices of health care professionals [5]. In the USA, improving health literacy education for health care professionals is an identified key initiative by numerous stakeholders. Reports issued by the American Medical Association (AMA) and Institute of Medicine (IOM) call for greater efforts to educate health professionals about health literacy and effective low-health literacy techniques; specifically, health care professional-patient communication strategies [8]. Improving health literacy for health care professionals is also a highlighted aspect of the U.S. National Action Plan to Improve Health Literacy [9]. In its influential report on health literacy, the IOM indicates that health care professionals and support staff have limited education, training, continuing education, and practice opportunities to develop skills that can improve their ability to address health literacy in their practice setting [5]. Evidence also shows that physician and non-physician health care professionals benefit from health literacy training and that even modest educational interventions can positively influence participants' selfperceived knowledge, skills, and planned behaviors regarding health literacy in the medical arena [10].

Health literacy can be considered a widespread issue of ethics and equity and is fundamental to reducing health care disparities. Policy priorities and growing evidence indicates a universal need for stakeholders to develop and implement health literacy initiatives into their routine practice in order to provide effective, client-centered care. The United Nations Economic and Social Council (ECOSOC) Ministerial Declaration of 2009 provides a clear mandate for stakeholders to develop action plans that address and promote health literacy in all aspects of health care [11]. In this vein, health literacy should not be viewed as the sole responsibility of individuals; rather, health care professionals must increase their efforts to incorporate health literacy into all aspects of medical education, practice, and policy initiatives [12]. Health literacy forms the basis for health beliefs, health care decisions, lifestyle choices, and how individuals navigate complex health care systems. Routine use of a universal precautions approach to health literacy can enhance program development, and improve efforts that address health and health equity by effectively meeting the needs of at-risk, marginalized, and disadvantaged societies. 


\section{Conclusion}

The potential effects of low-health literacy are wide-ranging and substantial. Extensive promotion and routine use of health literacy initiatives, such as universal precautions, can lead to an improvement in overall population health, a decline in the use of unnecessary health services, and a collective reduction in health care costs. Systemic use of a universal precautions approach to health literacy can help to reduce complexities associated with health care and increase patient understanding of health information in a guiltless context that supports all levels of health literacy. It is critical that health care organizations provide health literacy training to their staff in order to provide client-centered, evidence-based care to their patients. As health care professionals, we must seize every opportunity to become change agents and develop leadership qualities to effectively service clients, cohorts, and the medical profession at large. The widespread use of health literacy universal precautions in all aspects of health care will help to improve the care and outcomes for at-risk patients and populations, while cultivating the values, ethics, and principles associated with optimal health care.

\section{References}

1. Geboers B, Brainard JS, Loke YK, Jansen CJ, et al. (2015). The association of health literacy with adherence in older adults, and its role in interventions: a systematic meta-review. Biomed Central Public Health 15(903): 1-10.

2. Agency for Healthcare Research and Quality. (2018). Connecticut rehab facility boosts health literacy skills with ahrq toolkit.

3. Brega, AG, Barnard, J, Mabachi, NM, Weiss, BD, DeWalt, DA et al. (2015) AHRQ health literacy universal precautions toolkit, second edition.

4. AHRQ Health Literacy Universal Precautions Toolkit (2015) AHRQ-Agency for healthcare research and quality.
5. Mackert M, Ball K, Lopez N (2011) Health literacy awareness training for healthcare workers: Improving knowledge and intentions to use clear communication techniques. Patient Education and Counseling 85 e225-e228.

6. Sudore RL, Schillinger D (2009) Interventions to improve care for patients with limited health literacy. Journal of Clinical Outcomes Management, 16(1): 20-29.

7. Liang L, Brach C (2017) Health literacy universal precautions are still a distant dream: analysis of u.s. data on health literate practices. Health Literacy Research and Practice 1(4): e216-230.

8. Green JA, Gonzaga AM, Cohen ED, Spagnoletti, CL (2014) Addressing health literacy through clear communication: a training program for internal medicine residents. Patient Education and Counseling 95(1): 76-82.

9. DeWalt DA, Broucksou, KA, Hawk, V, Brach, C, et al. (2011) Developing and testing the health literacy universal precautions toolkit. Nursing Outlook 59(2): 85-94.

10. Koenig VE, Provident, IM (2018) Workshop series for occupational therapists using the US Agency for Healthcare Research and Quality's Health Literacy Universal Precautions Toolkit and other supported tools. Health Education Journal 1-13. Retrieved from journals.sagepub.com/home/hej

11. The United Nations Economic and Social Council. (2009). Ministerial declaration: 2009 high-level segment: Implementing the internationally agreed goals and commitments in regard to global public health. http://www.un.org/en/ecosoc/julyhls/pdf09 /ministerial_declaration-2009.pdf

12. World Health Organization. (2016). Health Literacy: The mandate for health literacy. https://www.who.int/healthpromotion conferences/9gchp/health-literacy/en/ 